\title{
The function of miRNAs and their potential as therapeutic targets in burn-induced insulin resistance (Review)
}

\author{
YONGHUI YU and JIAKE CHAI
}

Department of Burn and Plastic Surgery, The First Affiliated Hospital of PLA General Hospital, Beijing 100048, P.R. China

Received May 4, 2014; Accepted December 3, 2014

DOI: $10.3892 / \mathrm{ijmm} .2014 .2023$

\begin{abstract}
Burns are common accidental injuries. The main clinical manifestations of severe burn injury are insulin resistance and high metabolism. Insulin resistance results in hyperglycemia, which may lead to skeletal muscle wasting and suspended wound healing. It also elevates the risk of infection and sepsis. Studies have indicated that insulin receptor (IR) and insulin receptor substrate 1 (IRS1) are essential factors involved in the regulation of blood glucose levels. Moreover, the suppression of the IR/IRS1 signaling pathway results in insulin resistance. Recent studies have also indicated that miRNAs, which are small non-coding RNAs consisting of 20-23 nucleotides, target the 3'-untranslated region (3'-UTR) of IRSI mRNA and attenuate protein translation. miRNAs also play an important role in the development of type II diabetes (T2D) and obesity-induced insulin resistance. In the present review, we discuss the involvement of miRNAs in burn-induced insulin resistance through the targeting of the IR/IRS1 signaling pathway. We also discuss the possibility of miRNAs a novel therapeutic target in insulin resistance in burn patients.
\end{abstract}

\section{Contents}

1. Introduction

2. Insulin resistance is a direct consequence of burn injury

3. Involvement of the insulin signaling pathway in glucose metabolism

4. Suppression of the insulin signaling pathway by burn injuries

5. Involvement of miRNAs in the regulation of insulin resistance

6. Potential role of miRNAs in clinical therapy

7. Conclusions

Correspondence to: Professor Jiake Chai, Department of Burn and Plastic Surgery, The First Affiliated Hospital of PLA General Hospital, 51 Fu Cheng Road, Haidian, Beijing 100048, P.R. China E-mail: cjk304@126.com

Key words: miRNA, burn injury, glucose metabolism, insulin resistance

\section{Introduction}

Mature miRNAs are small non-coding RNAs that consist of 19-23 nucleotides. The first miRNAs were characterized in C. elegans in 1993 (1). Subsequently, an increasing number of miRNAs were identified in plants and animals. To date, over 1,000 miRNAs have been identified in humans, which regulate approximately $60 \%$ of mammalian gene expression $(2,3)$. miRNA genes are transcribed as primary miRNAs by RNA polymerase II (4). Following transcription, the precursor miRNA (stem-loop with approximately 80 nucleotides) is generated by Drosha (5). Subsequently, the precursor miRNA is exported from the nucleus to the cytoplasm and digested into a mature miRNA by Dicer, an RNA polymerase III enzyme (6). The main function of miRNAs is to regulate gene expression at the translational level. miRNAs can bind to the 3'-untranslated region (3'-UTR) of a target mRNA and suppress its translation (1). Recent studies have indicated that miRNAs play an essential role in a variety of diseases, including cancer (7), type I (8) and type II diabetes (T2D) (9), autoimmunity disease (10), and cardiovascular diseases (11). Thus, miRNAs have a potential effect on clinical diagnosis, prognosis and therapy.

Burn injury is a complex trauma which is caused by factors such as heat, electricity, chemicals and radiation (12). Inflammation is one of the host responses to injury, and following burn injury, the levels of inflammatory mediators, such as tumor necrosis factor $\alpha$ (TNF- $\alpha)$ (13), transformation growth factor $\beta$ (TGF- $\beta$ ) (14), interleukin (IL)-2 and IL-6 (15), are markedly increased. Burn injury also leads to cardiovascular damage and enhances vascular permeability, which results in the loss of body fluid (16). Clinical studies have demonstrated that burn injury may induce insulin resistance and affect glucose and fat metabolism $(17,18)$. Insulin resistance contributes to the attenuation of wound healing, which enhances the risk of infection (19). As previously demonstrated, a topical insulin injection can accelerate wound healing in diabetes through the activation of the Akt and Erk signaling pathways (20).

Previous studies have indicated that miRNAs play a critical role in regulating insulin resistance induced by mitochondrial dysfunction or diabetes through the inhibition of insulin receptor substrate 1 (IRS1) protein translation $(21,22)$. The suppression of the insulin receptor (IR)/IRS1 signaling pathway is the key mechanism responsible for burn-induced 
insulin resistance; therefore, miRNAs may also be implicated in burn-induced insulin resistance. The identification of the specific miRNAs which are involved in burn-induced insulin resistance may lead to the development of novel therapeutic targets for clinical therapy.

\section{Insulin resistance is a direct consequence of burn injury}

A previous study using a rat model demonstrated that no difference in insulin secretion was detected between the sham and burn groups; however, the sensitivity of insulin was significantly suppressed in the burn group (23). Insulin resistance and hyperglycemia are crucial risk factors for increased mortality in patients with severe burn injuries (24). In another study on burned children, it was demonstrated that insulin resistance can last up to 3 years (25). Intensive insulin therapy is an efficient manner to control the blood glucose of severely burned patients, as it can decrease the risk of infection and sepsis, improve hepatic and rental function, and suppress acute inflammation (24).

\section{Involvement of the insulin signaling pathway in glucose metabolism}

Glucose is one of the most important energy sources for the human organism. It is usually stored in the liver and muscle cells in the form of glycogen (26). After eating, elevated blood glucose is converted into glycogen (27). During the conversion, blood glucose is firstly transported into cells by the plasma membrane protein glucose transporter (GLUT), and its four isoforms, GLUT1, GLUT2, GLUT3 and GLUT4, have been well-characterized (28). GLUT4 is primarily expressed in muscle and fat cells. The insulin signaling pathway plays an important role in regulating its translocation (Fig. 1). Insulin binds to the IR and induces the autophosphorylation of the receptor at tyrosine residues (29). Following autophosphorylation, the receptor further recruits the IRS and promotes its phosphorylation at tyrosine residues (30). Phosphorylated IRS subsequently binds to the regulatory subunit, p85, of the phosphoinositide-3 kinase (PI3K) and activates its catalytic subunit p110, which is responsible for stimulating the phosphoinositide-dependent kinase (PDK) (31). As the upstream kinase of Akt, activated PDK promotes the phosphorylation of Akt at Thr308 and Ser473 (32), and phosphorylated Akt mediates the translocation of GLUT from the cytoplasm to the membrane (33) (Fig. 1). Apart from its role in GLUT translocation, Akt has also been implicated in regulating glycogen synthesis. Glycogen synthase (GS) is a key enzyme involved in converting glucose into glycogen, and there are two isoforms in mammals, the muscle isoform (34) and the liver isoform (35). Both isoforms are inactivated due to phosphorylation at the $\mathrm{NH} 2$ - or $\mathrm{COOH}$-terminal residues mediated by glycogen synthesis kinase 3 (GSK3) (36). Insulin dephosphorylates and restores the function of GS through Akt- or protein kinase A-mediated phoshorylation and the inactivation of GSK3 $(37,38)$. In skeletal muscle, insulin enhances glycogen synthesis in the absence of GSK3 phosphorylation (39). Glucose- 6 phosphate induces glycogen synthesis through the activation of GS in a cyclic AMP-stimulated protein kinasedependent manner (40).

\section{Suppression of the insulin signaling pathway by burn injuries}

After a burn injury is sustained, the activation of the insulin signaling pathway is significantly suppressed, and blood glucose levels are markedly increased (41). The results from experiments carried out in our, as well as other laboratories have indicated that the levels of lipopolysaccharides (LPS), TNF- $\alpha$ and interleukins are increased following burn injury $(13,15)$. These factors are involved in the regulation of the phosphorylation and degradation of IRS1 which, in turn, results in insulin resistance (Fig. 2). LPS, the stimulator of inducible nitric oxide synthase (iNOS), plays an essential role in inducing hyperglycemia and insulin resistance, which can be restored by the iNOS inhibitor $(42,43)$. iNOS also enhances the ubiquitination and degradation of IRS1 (44). The deficiency of iNOS attenuates the burn-induced skeletal muscle insulin resistance (45). Glucose uptake is decreased following exposure to TNF- $\alpha$ (46). TNF- $\alpha$ inhibits the autophosphorylation of IR and its substrate IRS1 tyrosine phosphorylation (46). It can also suppress the function of IRS1 by triggering phosphorylation at Ser307 which induces the degradation of IRS1 (47-49). IL-6 has been shown to induce insulin resistance in HepG2 cells (50) and 3T3-L1 adipocytes (51), which can promote IRS1 degradation by upregulating the expression of the suppressor of cytokine signaling 3 (SOCS3) (52). IL-1 $\beta$ induces adipocyte insulin resistance through the downregulation of IRS1 (53). Due to the burn-induced IRS1 degradation, the interaction between IRS1 and PI3K is repressed, and insulin stimulates $\mathrm{PKB} / \mathrm{Akt}$ activation, which is impaired after burn injury (54). Subsequently, the phosphorylation of GSK3 $\beta$ at Ser9 mediated by activated Akt is decreased; the enhanced activity of GSK3 $\beta$ has been detected in the skeletal muscle of rats following burn injury (55). Thus, the phosphorylation of GS mediated by GSK3 is augmented, and the conversion of glucose into glycogen is significantly attenuated (Fig. 2). Taken together, these data indicate that the TNF- $\alpha$-, LPS- or IL-induced IRS1 protein degradation is involved in promoting burn-induced insulin resistance and hyperglycemia.

\section{Involvement of miRNAs in the regulation of insulin resistance}

As small non-coding RNAs, miRNAs play a pivotal role in post-transcriptional regulation. miRNAs can bind to and promote the deadenylation and degradation of target mRNAs $(56,57)$. Translational repression is another important function of miRNAs. It can directly bind to the 3'-UTR of target mRNAs and inhibit the translational initiation (58). Studies have demonstrated that miRNAs are involved in the regulation of multiple insulin resistance-induced diseases (Fig. 3). In T2D, miR-144 has been shown to promote insulin resistance by directly targeting IRSI mRNA (22). The suppression of IRS1 mediated by miR-126 has also been shown to result in mitochondrial dysfunction and insulin resistance (21). The sitmulation of Akt activation by insulin is critical for glycometabolism, and the obesity-induced miR-143 overexpression has been shown to lead to hyperglycemia by inactivating the Akt signaling pathway (59). A study using let-7 family transgenic mice demonstrated that let-7 overexpression 


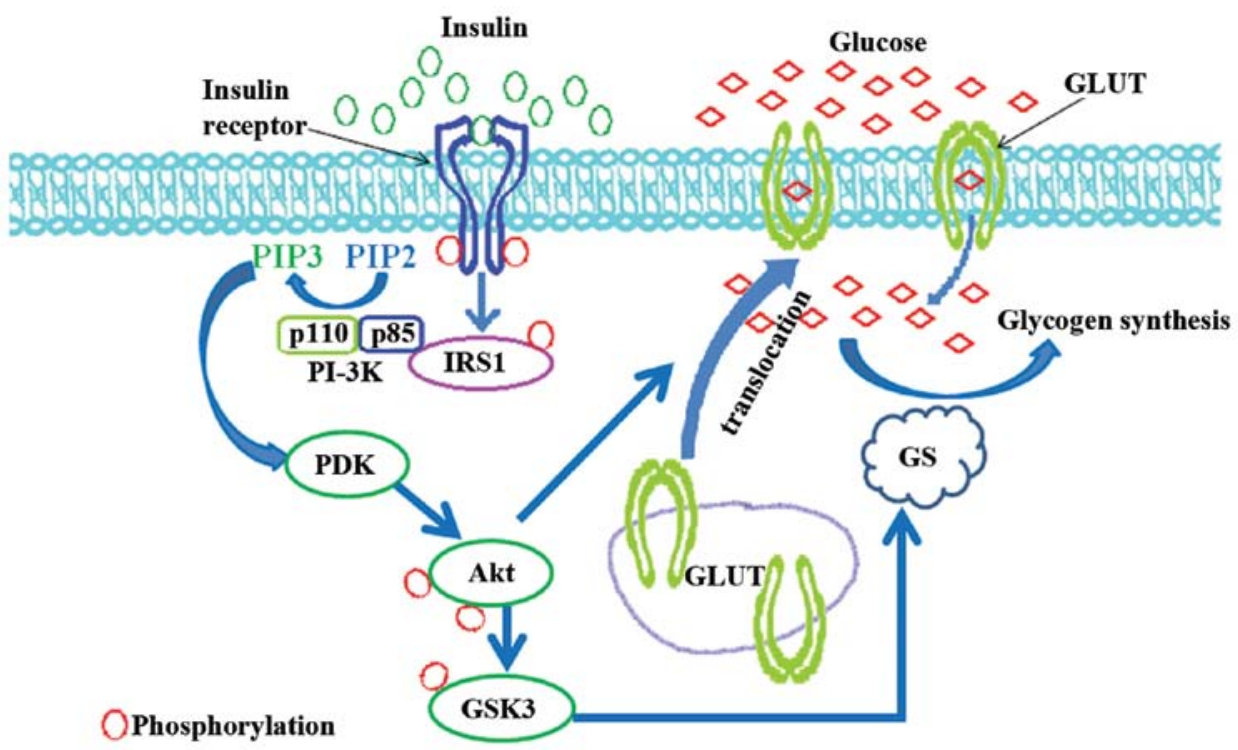

Figure 1. Schematic diagram of the inolvement of hte insulin signaling pathway in the regulation of glucose transport and glycogen synthesis. Insulin binds to its transmembrane receptor, insulin receptor (IR), and promotes its autophosphorylation at tyrosine residues (p-IR). Activated p-IR recruits IR substrate (IRS) and enhances its activation by mediating its phosphorylation (p-IRS). p-IRS subsequently binds to $\mathrm{p} 85$, the regulatory subunit of phosphoinositide-3 kinase (PI3K), and elevates the activation of its catalytic subunit p110, which subsequently activates phosphoinositide-dependent kinase (PDK). As the upstream kinase of Akt, PDK promotes the phosphorylation of Akt (p-Akt) at Thr308 and Ser473. Activated Akt regulates glucose metabolism in two pathways. One is promoting glucose transporter GLUT translocation from the cytoplasm to the membrane, which mediates glucose uptake; another one is repressing the function of glycogen synthesis kinase 3 (GSK3) by enhancing its phosphorylation at Ser9, and then enhancing the activation of GS and promoting glycogen synthesis.

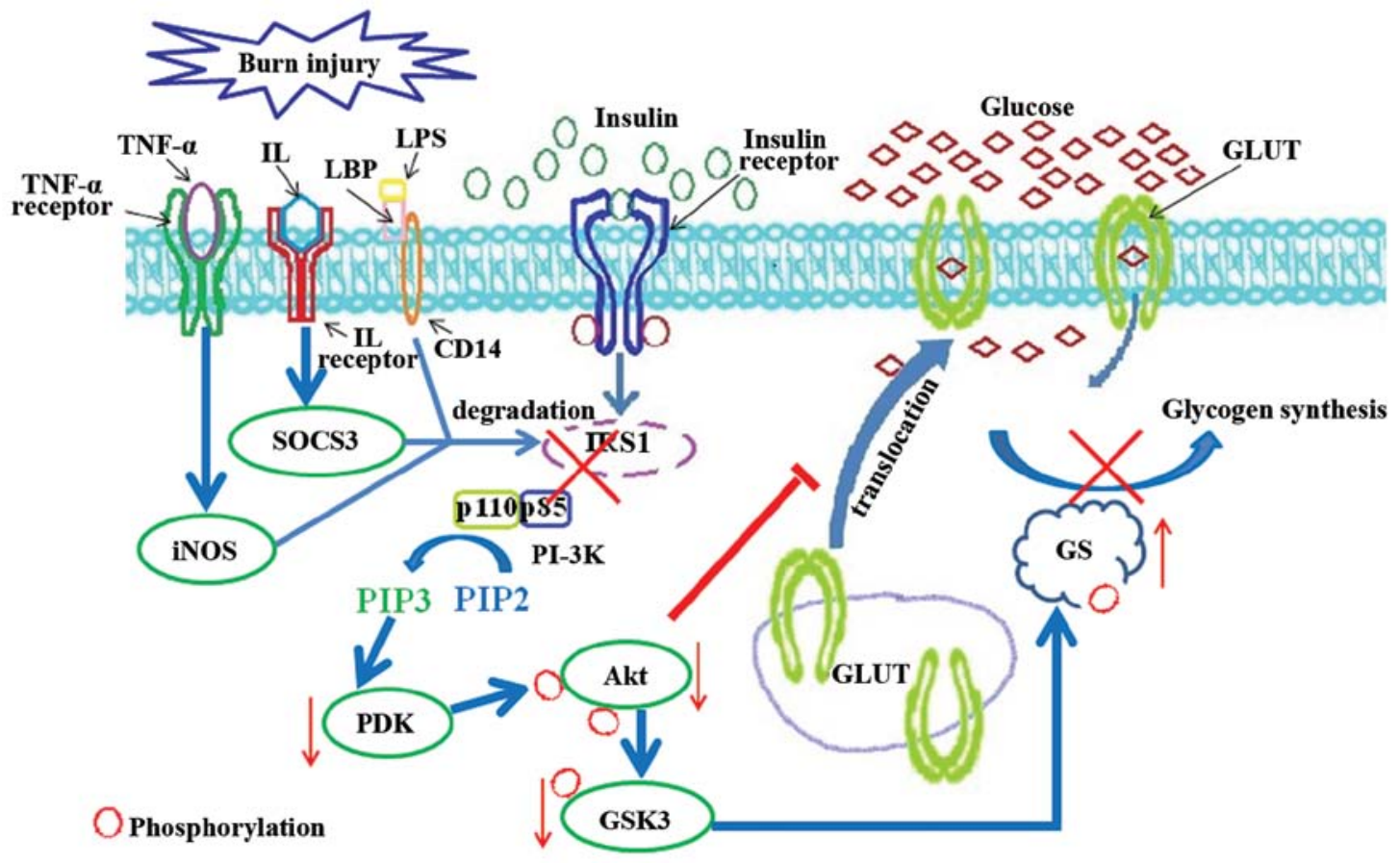

Figure 2. Schematic diagram of burn-induced insulin resistance through the suppression of the phosphoinositide-3 kinase (PI3K)/Akt signaling pathway mediated by insulin receptor substrate 1 (IRS1) degradation. After burn injury, the blood concentration of tumor necrosis factor (TNF)- $\alpha$, interleukin (IL) and lipopolysacchride (LPS) is significantly increased. TNF- $\alpha$ binds to its receptor and induces inducible nitric oxide synthase (iNOS) production. ILs, IL-6 in particular, bind to corresponding receptors and promote the expression of suppressor of cytokine signaling-3 (SOCS3). LPS binds to CD14 with the help of the LPS binding protein (LBP) and activates the intracellular signaling pathway. All the cytokines induce IRS1 protein degradation, which suppresses the PI3K/Akt signaling pathway, and subsequently suppresses glucose transporter (GLUT) translocation and glycogen synthesis, which results in burn-induced insulin resistance and hyperglycemia.

may contribute to the development of T2D (60). Protein tyrosine phosphatase 1B (PTP1B) impairs the insulin signaling pathway through the dephosphorylation of IR at tyrosine residues. The 3'-UTR of PTPIB mRNA is the target of miR-122, 


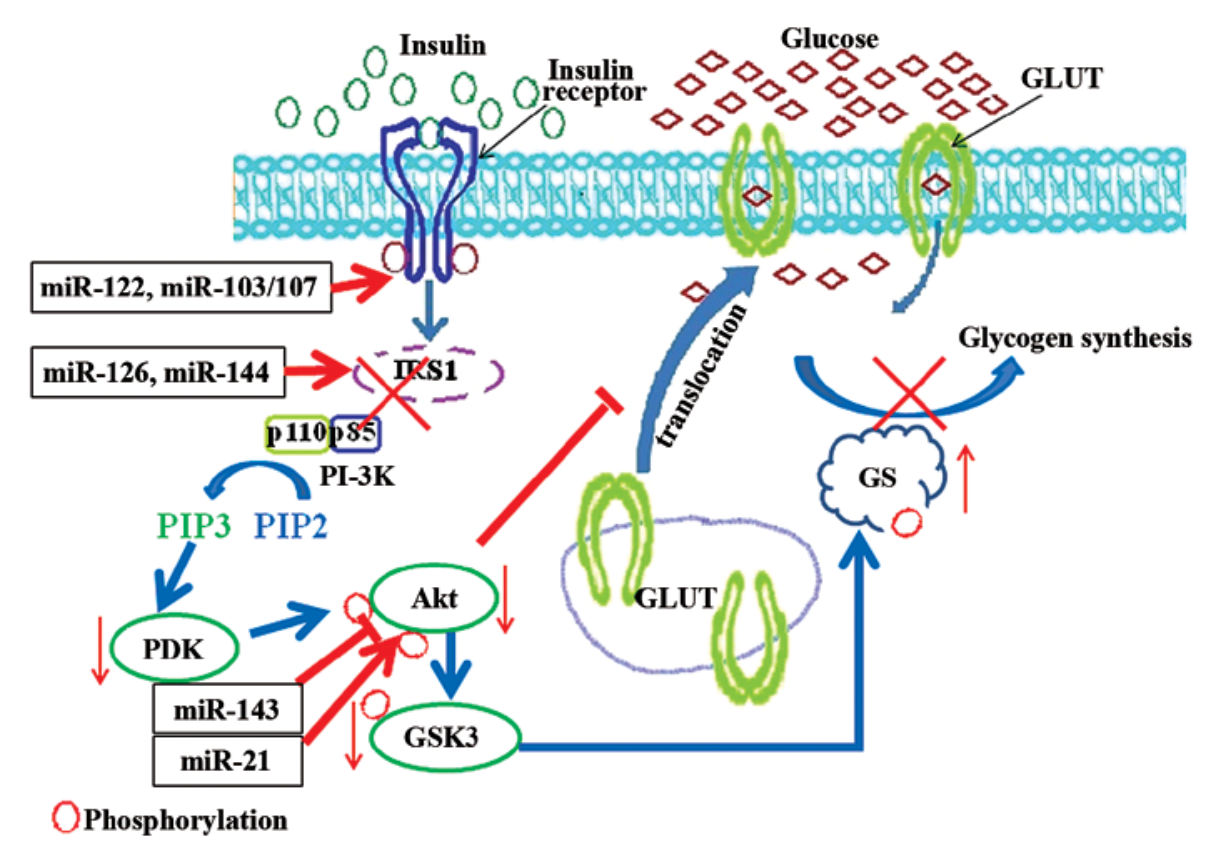

Figure 3. The miRNAs involved in regulating the insulin signaling pathway and glucose metabolism. miRNAs play an important role in the regulation of insulin signaling. Protein tyrosine phosphatase 1B (PTP1B) is the phosphatase of the insulin receptor (IR), and miR-122 inhibits the production of PTP1B and promotes the activation of the insulin signaling pathway. miR-103/107 also elevates the caveolin-mediated IR activation and enhances insulin sensitivity. miR-126 and miR-144 directly bind to the 3'-untranslated region (3'-UTR) of insulin receptor substrate 1 (IRS1) mRNA and suppress its translation, which abrogates the connection with phosphoinositide-3 kinase (PI-3K) and induces insulin resistance. In obesity-induced insulin resistance, upregulated miR-143 impairs the insulin-induced Akt activation. In adipocytes, The repressed expression of miR-21, which directly targets the phosphatase and tensin homolog deleted on chromosome 10 (PTEN), the key phosphotase of Akt, results in Akt inactivation and impairs insulin-mediated glucose metabolism.

and decreased miR-122 expression has been shown to result in hepatic insulin resistance (61). In mouse models of obesity, miR-103/107 is upregulated. The blockage of miR-103/107 has been shown to promote insulin sensitivity by elevating caveolin-1-mediated IR activation (62). Phosphatase and tensin homolog deleted on chromosome 10 (PTEN), the direct target of miR-21 (63), is the key phosphotase of Akt which can negatively regulate the Akt signaling pathway. In insulinresistant adipocytes, the suppressed expression of miR-21 and impaired Akt signaling pathway has been observed (64). The transport of glucose is also regulated by miRNAs, and the transmembrane protein GLUTs play an essential role in glucose transport. Elevated miR-133 levels have been shown to reduce the insulin-stimulated glucose uptake by downregulating GLUT4 expression (65). In cardiomyocytes, miR-223 has been shown to promote GLUT4 expression and increase glucose uptake (66). Insulin resistance is the intrinsic complication of polycystic ovary syndrome (PCOS), and overexpressed miR-93 in patients with PCOS binds to the 3'-UTR of GLUT4 mRNA and reduces its protein translation (67). Microarray analysis has further indicated that the expression of several miRNAs is altered following burn injury. In comparison with normal skin tissue, a total of 32 upregluated and 34 downregulated miRNAs were identified in the skin tissue of patients who sustained burn injuries (68). The expression levels of miR-144 in the skin tissue of the burned patients, which can directly target the 3'-UTR of IRSI mRNA (22), were 16-fold higher than those in normal skin tissue (68). This suggests that miRNAs, such as miR-144, play an essential role in promoting burn-induced insulin resistance by suppressing the activation of the IR/IRS signaling pathway.

\section{Potential role of miRNAs in clinical therapy}

Although miRNAs were only discovered 20 years ago, their molecular mechanisms of action involving the repression of target gene expression have been elucidated. Moreover, evidence indicates that miRNAs are associated with the development of a number of human diseases. The process from the time of discovery of an miRNA to the development of clinical therapeutic drug targets is rapidly approaching. miR-34a has been shown to suppress the development of prostate and lung cancer $(69,70)$, and the use of a miR-34a mimic is currently in the developmental stage for cancer therapy (www. iptonline. com, The Therapeutic Potential of microRNAs). Another miRNA, miR-208, which is involved in promoting chronic heart failure (71), is also undergoing investigation in preclinical trials (www. iptonline.com, The Therapeutic Potential of microRNAs). Its antagonist is expected to be used in the therapy of heart disease. miR-122 has been shown to be associated with hepatitis $\mathrm{C}$ virus infection (72), and its antagonist, miravirsen, has undergone phase II clinical trials for the therapy of patients with hepatitis $C$ virus (73). Miravirsen may be the first miRNArelated drug for clinical therapy. Taken together, the mimics or antagonists of miRNAs are expected to be widely used in clinical therapy.

\section{Conclusions}

In the response to burn injury, the expression of several miRNAs, including insulin resistance-associated miRNAs, is altered. This change may play a pivotal role in mediating burn-induced insulin resistance, which results in hyperglycemia and reduces 
wound healing. Further research focusing on the involvement of miRNAs in the regulation of burn-induced insulin resistance may lead to the development of novel therapeutic targets for the treatment of burn injuries.

\section{Acknowledgements}

The present study was supported by grants from the National Science Foundation of China (NSFC81120108014 and NSFC81471873), the Beijing Natural Science Foundation (7144250) and the China Postdoctoral Science Foundation (2013M532200).

\section{References}

1. Lee RC, Feinbaum RL and Ambros V: The C. elegans heterochronic gene lin-4 encodes small RNAs with antisense complementarity to lin-14. Cell 75: 843-854, 1993.

2. Bentwich I, Avniel A, Karov Y, et al: Identification of hundreds of conserved and nonconserved human microRNAs. Nat Genet 37: 766-770, 2005

3. Lewis BP, Burge CB and Bartel DP: Conserved seed pairing, often flanked by adenosines, indicates that thousands of human genes are microRNA targets. Cell 120: 15-20, 2005.

4. Lee Y, Kim M, Han J, et al: MicroRNA genes are transcribed by RNA polymerase II. EMBO J 23: 4051-4060, 2004.

5. Zeng $\mathrm{Y}$ and Cullen BR: Efficient processing of primary microRNA hairpins by Drosha requires flanking nonstructured RNA sequences. J Biol Chem 280: 27595-27603, 2005.

6. Andl T, Murchison EP, Liu F, et al: The miRNA-processing enzyme dicer is essential for the morphogenesis and maintenance of hair follicles. Curr Biol 16: 1041-1049, 2006.

7. Visone R and Croce CM: MiRNAs and cancer. Am J Pathol 174: $1131-1138,2009$.

8. Argyropoulos C, Wang K, McClarty S, et al: Urinary microRNA profiling in the nephropathy of type 1 diabetes. PLoS One 8: e54662, 2013.

9. van de Bunt M, Gaulton KJ, Parts L, et al: The miRNA profile of human pancreatic islets and beta-cells and relationship to type 2 diabetes pathogenesis. PLoS One 8: e55272, 2013.

10. McMichael AJ, Borrow P, Tomaras GD, Goonetilleke N and Haynes BF: The immune response during acute HIV-1 infection: clues for vaccine development. Nat Rev Immunol 10: 11-23, 2010.

11. Ono K, Kuwabara Y and Han J: MicroRNAs and cardiovascular diseases. FEBS J 278: 1619-1633, 2011.

12. Evers LH, Bhavsar D and Mailander P: The biology of burn injury. Exp Dermatol 19: 777-783, 2010.

13. Duan H, Chai J, Sheng Z, et al: Effect of burn injury on apoptosis and expression of apoptosis-related genes/proteins in skeletal muscles of rats. Apoptosis 14: 52-65, 2009.

14. Nishimura T, Nishiura T, deSerres S, Nakagawa T, Brenner DA and Meyer AA: Impact of burn injury on hepatic TGF-beta1 expression and plasma TGF-beta1 levels. J Trauma 48: 39-44, 2000.

15. Kowal-Vern A, Walenga JM, Hoppensteadt D, Sharp-Pucci M and Gamelli RL: Interleukin-2 and interleukin- 6 in relation to burn wound size in the acute phase of thermal injury. J Am Coll Surg 178: 357-362, 1994.

16. Soejima K, Traber LD, Schmalstieg FC, et al: Role of nitric oxide in vascular permeability after combined burns and smoke inhalation injury. Am J Respir Crit Care Med 163: 745-752, 2001.

17. Cree MG, Zwetsloot JJ, Herndon DN, et al: Insulin sensitivity and mitochondrial function are improved in children with burn injury during a randomized controlled trial of fenofibrate. Ann Surg 245: 214-221, 2007.

18. Cree MG, Aarsland A, Herndon DN and Wolfe RR: Role of fat metabolism in burn trauma-induced skeletal muscle insulin resistance. Crit Care Med 35: S476-S483, 2007.

19. Sharp A and Clark J: Diabetes and its effects on wound healing. Nurs Stand 25: 41-47, 2010.

20. Lima MH, Caricilli AM, de Abreu LL, et al: Topical insulin accelerates wound healing in diabetes by enhancing the AKT and ERK pathways: a double-blind placebo-controlled clinical trial. PLoS One 7: e36974, 2012.
21. Ryu HS, Park SY, Ma D, Zhang J and Lee W: The induction of microRNA targeting IRS-1 is involved in the development of insulin resistance under conditions of mitochondrial dysfunction in hepatocytes. PLoS One 6: e17343, 2011.

22. Karolina DS, Armugam A, Tavintharan S, et al: MicroRNA 144 impairs insulin signaling by inhibiting the expression of insulin receptor substrate 1 in type 2 diabetes mellitus. PLoS One 6: e22839, 2011.

23. Frayn KN: Effects of burn injury on insulin secretion and on sensitivity to insulin in the rat in vivo. Eur J Clin Invest 5: 331-337, 1975.

24. Jeschke MG, Kulp GA, Kraft R, et al: Intensive insulin therapy in severely burned pediatric patients: a prospective randomized trial. Am J Respir Crit Care Med 182: 351-359, 2010.

25. Gauglitz GG, Herndon DN, Kulp GA, Meyer WJ III and Jeschke MG: Abnormal insulin sensitivity persists up to three years in pediatric patients post-burn. J Clin Endocrinol Metab 94: 1656-1664, 2009

26. Kokubun E, Hirabara SM, Fiamoncini J, Curi R and Haebisch H: Changes of glycogen content in liver, skeletal muscle, and heart from fasted rats. Cell Biochem Funct 27: 488-495, 2009.

27. Chari-Bitron A, Lepkovsky S, Lemmon RM and Dimick MK: Conversion of glucose to glycogen after ingestion of a high-carbohydrate diet. Am J Physiol 198: 787-792, 1960.

28. Bell GI, Kayano T, Buse JB, et al: Molecular biology of mammalian glucose transporters. Diabetes Care 13: 198-208, 1990.

29. Kasuga M, Zick Y, Blithe DL, Crettaz M and Kahn CR: Insulin stimulates tyrosine phosphorylation of the insulin receptor in a cell-free system. Nature 298: 667-669, 1982.

30. Boura-Halfon S and Zick Y: Phosphorylation of IRS proteins, insulin action, and insulin resistance. Am J Physiol Endocrinol Metab 296: E581-E591, 2009.

31. Metz HE and Houghton AM: Insulin receptor substrate regulation of phosphoinositide 3-kinase. Clin Cancer Res 17: 206-211, 2011.

32. Bhaskar PT and Hay N: The two TORCs and Akt. Dev Cell 12: 487-502, 2007.

33. Thorell A, Hirshman MF, Nygren J, et al: Exercise and insulin cause GLUT-4 translocation in human skeletal muscle. Am J Physiol 277: E733-E741, 1999.

34. Browner MF, Nakano K, Bang AG and Fletterick RJ: Human muscle glycogen synthase cDNA sequence: a negatively charged protein with an asymmetric charge distribution. Proc Natl Acad Sci USA 86: 1443-1447, 1989

35. Bai G, Zhang ZJ, Werner R, Nuttall FQ, Tan AW and Lee EY: The primary structure of rat liver glycogen synthase deduced by cDNA cloning. Absence of phosphorylation sites 1a and 1b. J Biol Chem 265: 7843-7848, 1990.

36. Hojlund K, Birk JB, Klein DK, et al: Dysregulation of glycogen synthase $\mathrm{COOH}$ - and $\mathrm{NH}_{2}$-terminal phosphorylation by insulin in obesity and type 2 diabetes mellitus. J Clin Endocrinol Metab 94: 4547-4556, 2009.

37. Cross DA, Alessi DR, Cohen P, Andjelkovich $M$ and Hemmings BA: Inhibition of glycogen synthase kinase- 3 by insulin mediated by protein kinase B. Nature 378: 785-789, 1995 .

38. Fang X, Yu SX, Lu Y, Bast RC Jr, Woodgett JR and Mills GB: Phosphorylation and inactivation of glycogen synthase kinase 3 by protein kinase A. Proc Natl Acad Sci USA 97: 11960-11965, 2000.

39. Bouskila M, Hirshman MF, Jensen J, Goodyear LJ and Sakamoto K: Insulin promotes glycogen synthesis in the absence of GSK3 phosphorylation in skeletal muscle. Am J Physiol Endocrinol Metab 294: E28-E35, 2008.

40. Villar-Palasi C and Guinovart JJ: The role of glucose 6-phosphate in the control of glycogen synthase. FASEB J 11: 544-558, 1997.

41. Ikezu T, Okamoto T, Yonezawa K, Tompkins RG and Martyn JA: Analysis of thermal injury-induced insulin resistance in rodents. Implication of postreceptor mechanisms. J Biol Chem 272: 25289-25295, 1997.

42. Pilon G, Charbonneau A, White PJ, et al: Endotoxin mediated-iNOS induction causes insulin resistance via ONOO induced tyrosine nitration of IRS-1 in skeletal muscle. PLoS One 5: e15912, 2010.

43. Sugita H, Kaneki M, Tokunaga E, et al: Inducible nitric oxide synthase plays a role in LPS-induced hyperglycemia and insulin resistance. Am J Physiol Endocrinol Metab 282: E386-E394, 2002.

44. Sugita H, Fujimoto M, Yasukawa T, et al: Inducible nitric-oxide synthase and NO donor induce insulin receptor substrate-1 degradation in skeletal muscle cells. J Biol Chem 280: 14203-14211, 2005. 
45. Sugita M, Sugita H, Kim M, et al: Inducible nitric oxide synthase deficiency ameliorates skeletal muscle insulin resistance but does not alter unexpected lower blood glucose levels after burn injury in C57BL/6 mice. Metabolism 61: 127-136, 2012.

46. Hotamisligil GS, Murray DL, Choy LN and Spiegelman BM: Tumor necrosis factor alpha inhibits signaling from the insulin receptor. Proc Natl Acad Sci USA 91: 4854-4858, 1994.

47. Pederson TM, Kramer DL and Rondinone CM: Serine/threonine phosphorylation of IRS-1 triggers its degradation: possible regulation by tyrosine phosphorylation. Diabetes 50: 24-31, 2001.

48. Zhang Q, Carter EA, Ma BY, White M, Fischman AJ and Tompkins RG: Molecular mechanism(s) of burn-induced insulin resistance in murine skeletal muscle: role of IRS phosphorylation. Life Sci 77: 3068-3077, 2005.

49. Rui L, Aguirre V, Kim JK, et al: Insulin/IGF-1 and TNF-o stimulate phosphorylation of IRS-1 at inhibitory Ser $^{307}$ via distinct pathways. J Clin Invest 107: 181-189, 2001

50. Senn JJ, Klover PJ, Nowak IA and Mooney RA: Interleukin-6 induces cellular insulin resistance in hepatocytes. Diabetes 51: 3391-3399, 2002.

51. Rotter V, Nagaev I and Smith U: Interleukin-6 (IL-6) induces insulin resistance in 3T3-L1 adipocytes and is, like IL-8 and tumor necrosis factor- $\alpha$, overexpressed in human fat cells from insulin-resistant subjects. J Biol Chem 278: 45777-45784, 2003.

52. Zhang L, Du J, Hu Z, et al: IL-6 and serum amyloid A synergy mediates angiotensin II-induced muscle wasting. J Am Soc Nephrol 20: 604-612, 2009.

53. Jager J, Gremeaux T, Cormont M, Le Marchand-Brustel $Y$ and Tanti JF: Interleukin-1beta-induced insulin resistance in adipocytes through down-regulation of insulin receptor substrate-1 expression. Endocrinology 148: 241-251, 2007.

54. Sugita H, Kaneki M, Sugita M, Yasukawa T, Yasuhara S and Martyn JA: Burn injury impairs insulin-stimulated Akt/PKB activation in skeletal muscle. Am J Physiol Endocrinol Metab 288: E585-E591, 2005.

55. Fang CH, Li B, James JH, et al: GSK-3 $\beta$ activity is increased in skeletal muscle after burn injury in rats. Am J Physiol Regul Integr Comp Physiol 293: R1545-R1551, 2007.

56. Beilharz TH, Humphreys DT, Clancy JL, et al: microRNA-mediated messenger RNA deadenylation contributes to translational repression in mammalian cells. PLoS One 4: e6783, 2009.

57. Behm-Ansmant I, Rehwinkel J, Doerks T, Stark A, Bork P and Izaurralde E: mRNA degradation by miRNAs and GW182 requires both CCR4:NOT deadenylase and DCP1:DCP2 decapping complexes. Genes Dev 20: 1885-1898, 2006.

58. Mathonnet G, Fabian MR, Svitkin YV, et al: MicroRNA inhibition of translation initiation in vitro by targeting the cap-binding complex eIF4F. Science 317: 1764-1767, 2007.

59. Jordan SD, Kruger M, Willmes DM, et al: Obesity-induced overexpression of miRNA-143 inhibits insulin-stimulated AKT activation and impairs glucose metabolism. Nat Cell Biol 13: 434-446, 2011
60. Frost RJ and Olson EN: Control of glucose homeostasis and insulin sensitivity by the Let-7 family of microRNAs. Proc Natl Acad Sci USA 108: 21075-21080, 2011.

61. Yang YM, Seo SY, Kim TH and Kim SG: Decrease of microRNA-122 causes hepatic insulin resistance by inducing protein tyrosine phosphatase $1 \mathrm{~B}$, which is reversed by licorice flavonoid. Hepatology 56: 2209-2220, 2012.

62. Trajkovski M, Hausser J, Soutschek J, et al: MicroRNAs 103 and 107 regulate insulin sensitivity. Nature 474: 649-653, 2011.

63. Zhang JG, Wang JJ, Zhao F, Liu Q, Jiang K and Yang GH: MicroRNA-21 (miR-21) represses tumor suppressor PTEN and promotes growth and invasion in non-small cell lung cancer (NSCLC). Clin Chim Acta 411: 846-852, 2010.

64. Ling HY, Hu B, Hu XB, et al: MiRNA-21 reverses high glucose and high insulin induced insulin resistance in 3T3-L1 adipocytes through targeting phosphatase and tensin homologue. Exp Clin Endocrinol Diabetes 120: 553-559, 2012.

65. Horie T, Ono K, Nishi H, et al: MicroRNA-133 regulates the expression of GLUT4 by targeting KLF15 and is involved in metabolic control in cardiac myocytes. Biochem Biophys Res Commun 389: 315-320, 2009

66. Lu H, Buchan RJ and Cook SA: MicroRNA-223 regulates Glut4 expression and cardiomyocyte glucose metabolism. Cardiovasc Res 86: 410-420, 2010.

67. Chen YH, Heneidi S, Lee JM, et al: miRNA-93 inhibits GLUT4 and is overexpressed in adipose tissue of polycystic ovary syndrome patients and women with insulin resistance. Diabetes 62: 2278-2286, 2013.

68. Liang P, Lv C, Jiang B, et al: MicroRNA profiling in denatured dermis of deep burn patients. Burns 38: 534-540, 2012.

69. Liu C, Kelnar K, Liu B, et al: The microRNA miR-34a inhibits prostate cancer stem cells and metastasis by directly repressing CD44. Nat Med 17: 211-215, 2011.

70. Wiggins JF, Ruffino L, Kelnar K, et al: Development of a lung cancer therapeutic based on the tumor suppressor microRNA-34. Cancer Res 70: 5923-5930, 2010.

71. Callis TE, Pandya K, Seok HY, et al: MicroRNA-208a is a regulator of cardiac hypertrophy and conduction in mice. J Clin Invest 119: 2772-2786, 2009.

72. Henke JI, Goergen D, Zheng J, et al: microRNA-122 stimulates translation of hepatitis C virus RNA. EMBO J 27: 3300-3310, 2008

73. Janssen HL, Reesink HW, Lawitz EJ, et al: Treatment of HCV infection by targeting microRNA. N Engl J Med 368: 1685-1694, 2013. 